\title{
Pengenalan Dasar Pengkodingan Secara Daring pada SMK Pemda Lubuk Pakam Anita Sindar Sinaga ${ }^{1 *}$; Arjon Samuel Sitio ${ }^{2}$; Petti Sijabat ${ }^{3}$ \\ ${ }^{1}$ STMIK Pelita Nusantara \\ 1*simaktoita@gmail.com
}

\begin{abstract}
Abstrak
Penggunaan media pembelajaran dalam proses belajar mengajar merupakan salah satu upaya untuk meningkatkan efektivitas serta kualitas proses pembelajaran yang pada akhirnya dapat meningkatkan kualitas hasil belajar siswa. Media hasil teknologi contoh video dimanfaatkan sebagai media pembelajaran sehingga siswa dapat mengulang materi yang dibagikan. Kualitas skill SDM perlu ditingkatkan melalui pelatihan-pelatihan untuk menghadapi tantangan dunia kerja nantinya. Skill computing menjadi trend kemampuan yang diminati dalam era digital revolusi 4.0. Belajar pemograman MatLab dilaksanakan Tim Pengabdian guna mendorong ketertarikan siswa Kelas X SMK swasta Pemda Lubuk Pakam pada pemograman. Selain memanfaatkan variabel MatLab untuk belajar matematika, pada akhir pemebelajaran, siswa disarankan menghasilkan program sederhana.
\end{abstract}

Kata kunci: Belajar Daring, MatLab, Pengabdian Dosen, Coding

\section{Abstract}

The use of instructional media in the teaching and learning process is one of the efforts to improve the effectiveness and quality of the learning process which in turn can improve the quality of student learning outcomes. Media resulting from video sample technology are used as learning media so students can repeat the material shared. The quality of HR skills needs to be improved through training to face the challenges of the workforce later. Skill computing has become a trend of capability that is in demand in the digital revolution 4.0. Learning of MatLab programming is carried out by the Community Service Team to encourage the interest of students in class $X$ of the private SMK in Lubuk Pakam regional government in programming. In addition to utilizing the MatLab variable for learning mathematics, at the end of learning, students are advised to produce a simple program.

Keywords: Online Learning, MatLab, Lecturer Dedication, Coding

\section{Pendahuluan}

Pelaksanaan sistem pembelajaran secara daring memberikan peluang bagi pelajar untuk dapat mengikuti suatu pelajaran tanpa tatap muka, terarah pada capaian pembelajaran. Media hasil teknologi berbasis komputer merupakan cara menghasilkan atau menyampaikan materi dengan menggunakan sumbersumber yang berbasis mikroprosesor. Berbagai jenis aplikasi teknologi berbasis komputer dalam pengajaran umumnya dikenal sebagai computerassisted instruction (pengajaran dengan bantuan komputer). E-learning telah mempersingkat waktu pembelajaran dan mengakibatkan biaya studi lebih ekonomis. E-learning mempermudah interaksi antara peserta didik dengan bahan atau materi pelajaran, peserta didik dengan guru atau instruktur maupun sesama peserta didik.

SMK Swasta Pemda Lubuk Pakam, sekolah menengah kejuruan terletak di wilayah Kabupaten Deli Serdang. Sekolah Menengah Kejuruan ini menyelenggarakan berbagai jurusan kejuruan seperti Teknologi Komputer Jaringan (TKJ), tata busana, dan tata kecantikan. Sekolah menghendaki bahwa lulusan siswa-siswinya mampu menjadi lulusan yang siap Volume 2, Nomor 2, 2020

ISSN 2657-1439 (Print), ISSN 2684-7043 (Online) pakai dalam dunia pekerjaan sesuai dengan jurusan yang mereka geluti saat ini. Untuk itu, kualitas SDM perlu ditingkatkan melalui pelatihan-pelatihan softskill untuk menghadapi tantangan dunia kerja nantinya. Skill Computing menjadi trend kemampuan yang diminati dalam era digital revolusi 4.0.

MatLab (Matrix Laboratory) adalah sebuah lingkungan komputasi numerikal dan bahasa pemrograman komputer generasi keempat. MATLAB adalah sebuah bahasa dengan (high-performance) kinerja tinggi untuk komputasi masalah teknik. Matlab mengintegrasikan komputasi, visualisasi, dan pemrograman dalam suatu model yang sangat mudah untuk pakai dimana masalah-masalah dan penyelesaiannya diekspresikan dalam notasi matematika yang familiar. Penggunaan Matlab meliputi bidang-bidang matematika dan komputasi, pembentukan algorithm, akusisi data, pemodelan, simulasi, dan pembuatan prototipe, analisa data, eksplorasi, dan visualisasi, grafik keilmuan dan bidang rekayasa.

Permasalahan yang ditemukan tim pengabdian (Dosen Teknik Informatika STMIK Pelita Nusantara) 
dengan mitra (SMK Pemda Lubuk Pakam), kemampuan computing (pengkodingan) siswa mitra masih rendah. Untuk meningkatkan minat para siswa maka dilaksanakan kegiatan pembelajaran dalam bentuk training (online), ditujukan bagi siswa-siswi yang tertarik mengenal dasar pengkodingan MatLab. Belajar MatLab menjadi menarik didukung kemampuan mata pelajaran matematika.

Kegiatan Tri Dharma Perguruan Tinggi bagian pengabdian nyata para dosen sebagai bentuk kepedulian untuk meningkatkan kecerdasan warga negara Indonesia di Era Revolusi Industri 4.0 perlu dilakukan guna meningkatkan kemampuan siswa sekolah. Mitra Tri Dharma Perguruan Tinggi, SMK Pemda beralamat di Jalan Tengku Raja Muda No. 32, Petapahan, Kec. Lubuk Pakam, Kabupaten Deli Serdang, Sumatera Utara 20518.

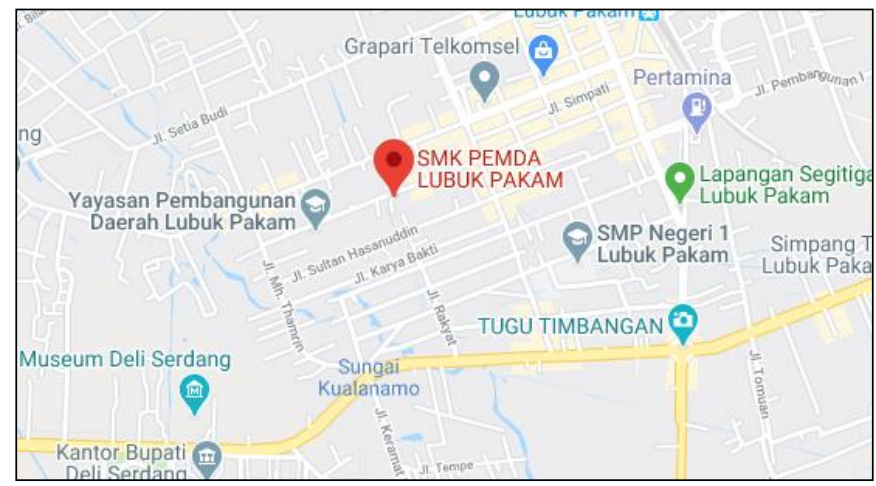

Gambar 1. Lokasi Pengabdian

\section{Bahan dan Metode}

Pembelajaran daring dilaksanakan selama 2 minggu, total 6 pertemuan atau selama 18 jam $(1,5$ jam/pertemuan), peserta siswa kelas x SMK Pemda Lubuk Pakam. Pembelajaran memanfaatkan youtube sebagai media belajar. Kendala pembelajaran disampaikan melalui classroom.

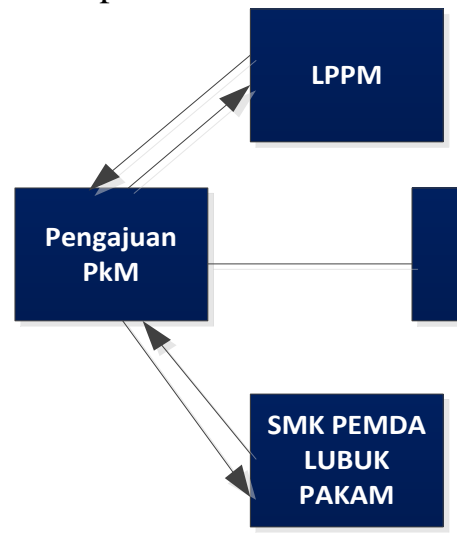

Gambar 2. Metode Pembelajaran

Tahap pembelajaran :

1) Persiapan

Pelaksanaan Tim Pengabdian melakukan analisa situasi di tempat mitra bertujuan memahami permasalahan yang muncul dan mencari solusi yang akan dilaksanakan.

2) Pelaksanaan

Pembelajaran secara daring memanfaatkan media online secara gratis menggunakan zoom dan classroom. Sebelum pelaksanaan, para siswa diarahkan sistem pembelajaran.

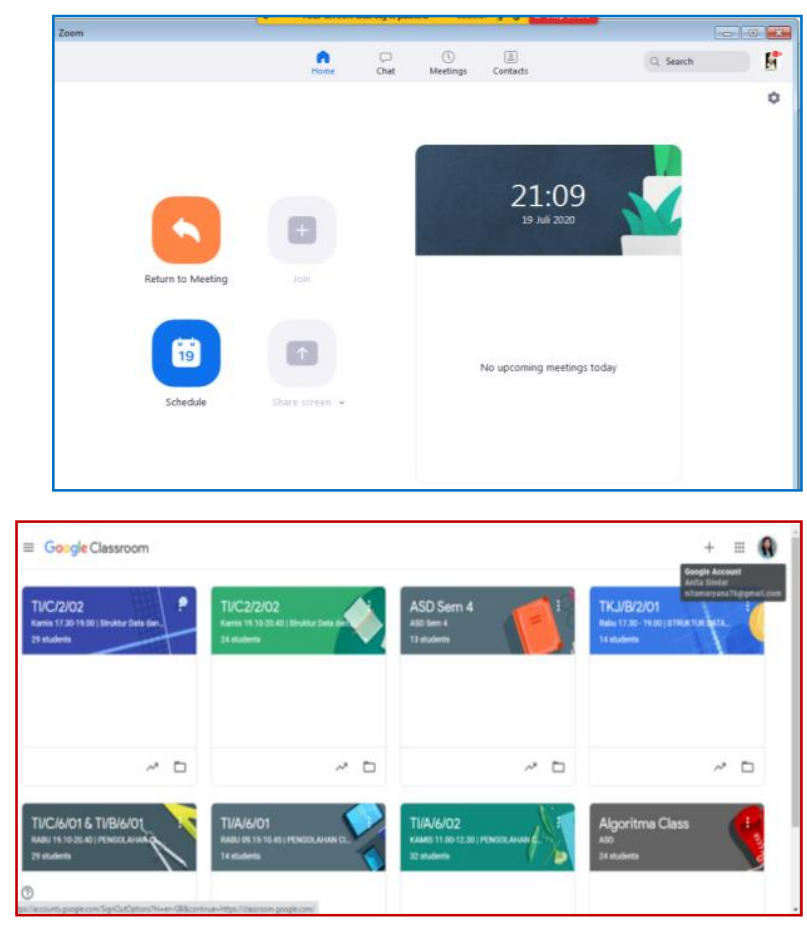

Gambar 3. Media Pembelajaran

3) Evaluasi

Sesion akhir pembelajaran, disarankan siswa membuatkan coding MatLab. Pengembangan video pembelajaran membutuhkan keterampilan berkolaborasi, percaya diri, dan sikap pantang menyerah. Banyak hal harus diperhatikan dalam pembuatan video pembelajaran. Aspek-aspek pembelajaran adalah membelajarkan siswa menggunakan asas pendidikan maupun teori belajar yang merupakan penentu utama keberhasilan pendidikan. Tujuan pembelajaran, menstimulasi penarikan kembali prasyarat pembelajaran, menyajikan materi, menyediakan bimbingan pembelajaran, memunculkan kinerja peserta didik, memberikan umpan balik, dan menilai kinerja.

\section{Hasil dan Pembahasan}

Coding adalah suatu proses menulis, menguji dan memperbaiki, dan memelihara kode yang akan membangun suatu program komputer. bahasa pemograman komputer ada-lah suatu standar untuk memerintahkan komputer. Bahasa pemograman ini merupakan suatu himpunan dari aturan sintaks dan semantik yang dipakai untuk mendefinisikan suatu program komputer. 
Penyampaian materi melalui daring dapat bersifat interaktif sehingga peserta belajar mampu berinteraksi dengan komputer sebagai media bela-jarnya. Sebagai salah satu contoh siswa yang menggunakan pembelajaran media elektronik atau menjalin hubungan (browsing, chatting, vidio-call) melalui media elektronik, dalam hal ini komputer dan internet nantinya akan memperoleh hasil belajar yang lebih efektif dan baik dari pada pembelajaran konvensional.

Sebelum pelaksanaan pelatihan secara daring, pemaparan tentang pemograman dijelaskan beberapa hal yang perlu diketahui oleh siswa sebelum pengkodingan, antara lain :

1. Pengetahuan dasar pemograman.

2. Memilih bahasa pemograman.

3. Mulai berlatih coding.

4. Temukan skill yang menjadi bidang pemograman.

Tujuan belajar pengkodingan menggunakan MatLab, yaitu :

1. Mengetahui bagian-bagian dasar yang penting dalam jendela Matlab.

2. Mengetahui dan dapat menggunakan dasar-dasar operasi dan variabel pada Matlab.

Materi pelatihan menggunakan MatLab R-2015, ada 2 topik materi pembelajaran :

1) Pengenalan MatLab

2) Variabel dan Operasi Dasar MatLab

Tabel 1. Jadwal Belajar Daring

\begin{tabular}{lll}
\hline \multirow{2}{*}{ Materi-1 } & \multicolumn{2}{c}{ Pengenalan MatLab } \\
\cline { 3 - 3 } 1 & Dasar MatLab & Pengenalan Tool-Tool MatLab dan \\
& & Fungsi \\
& & Variabel Pada Matlab \\
& \multirow{2}{*}{ Materi-2 } & Operasi Matematika pada MatLab \\
& & Coding Memanggil dan Menampilkan \\
& Script File & Objek \\
& & Coding Sederhana \\
\hline
\end{tabular}

MatLab digunakan oleh kalangan pelajar, teknisi, peneliti di Universitas, Institusi Penelitian maupun Industri untuk melakukan komputasi matematis dalam berbagai keperluan. MatLab biasanya digunakan untuk penelitian, pengembangan sistem dan desain sistem. Berbeda dengan bahasa pemrograman lainnya, MatLab merupakan bahasa pemrograman tertutup. Untuk kompilasi program anda harus menggunakan software dari MathWorks sendiri.

Pada topik pengenalan MatLab, diperkenalkan form utama tampilan Matlab dan tool-tool pendukung, Gambar 4.

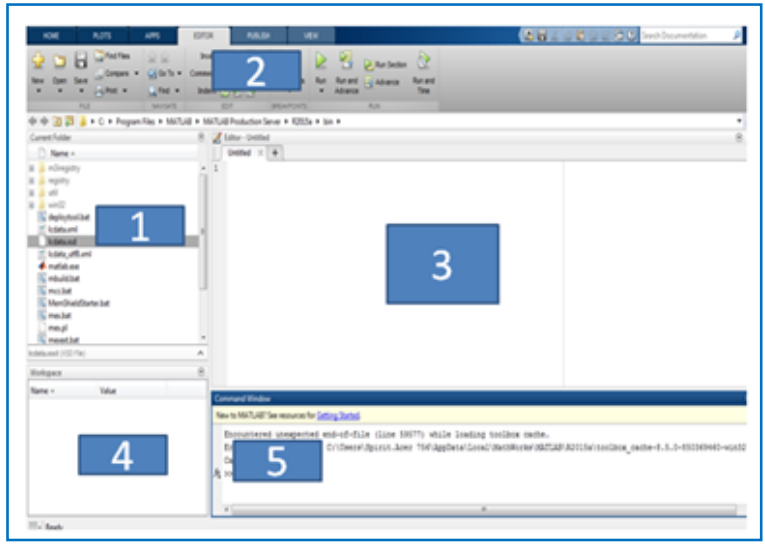

Gambar 4. Tampilan Window MatLab

Tampilan window MatLab 1)Current Folder, lokasi folder yang digunakan 2) Toolstrip, tombol-tombol fungsi perintah 3) Command Window, jendela perintah utama 4) Workspace, lokasi variabel-variabel yang digunakan 5) Command History, rekaman perintah yang sebelumnya telah dilakukan. Link video, https://youtu.be/cMhZpsYmxlc; link pembelajaran yang telah dilaksanakan pada Bulan Juni 2020.

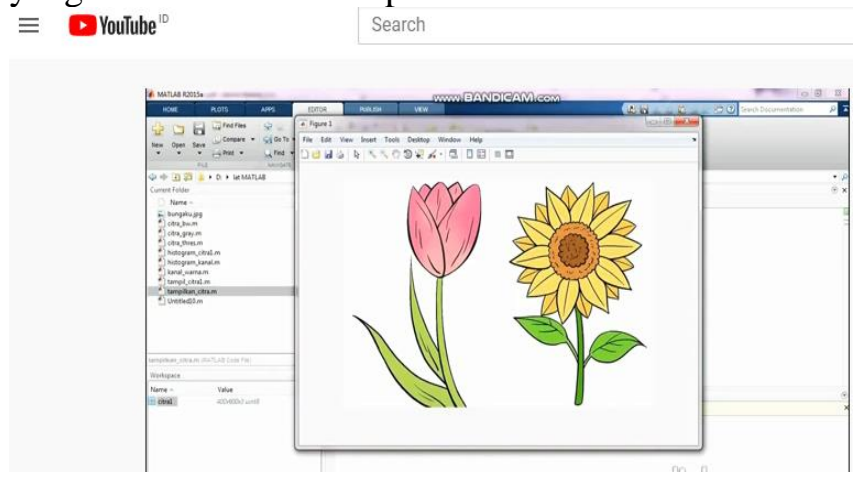

Gambar 5. Belajar Coding Secara Daring

A. Variabel pada MatLab

MatLab memiliki dua jenis tipe data yaitu Numeric dan String. User dapat langsung menuliskan variabel baru tanpa harus mendeklarasikannya. Command Window adalah jendela utama untuk melakukan eksekusi perintah, membuka jendela baru, menjalankan Toolbox dan manajemen software pada MatLab, contoh variabel pada MatLab. Langkah-langkah dasar yang perlu diketahui saat menggunakan program dengan MatLab.

Penunjuk Command Prompt ">>", menulis kode dimulai dengan klik pada penunjuk command prompt ">>". Setelah selesai menulis kode tekan "Enter" untuk menjalankan kode (run). Untuk membuat dan memberikan nilai numerik atau operasi komputasi, anda dapat menggunakan command window dengan menggunakan assignment operator "=". 


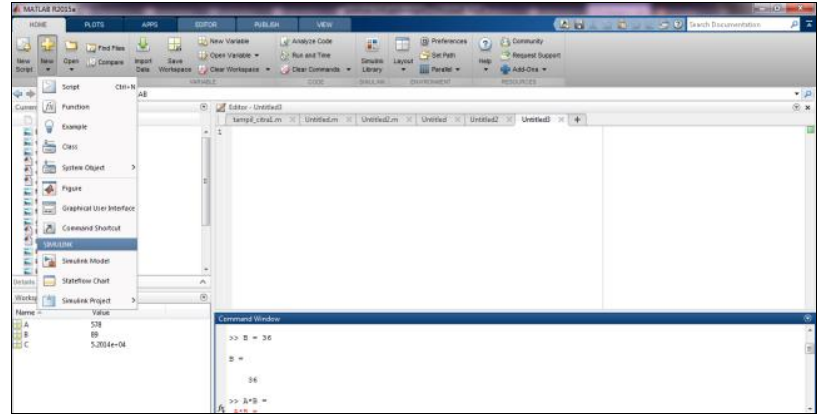

Gambar 6. Command Window

Sisi kiri assignment operator merupakan nama variabel dan sisi kanan merupakan nilai numerik atau operasi komputasi. Untuk melakukan eksekusi definisi variabel tekan enter. Gunakan Control S (Save), siapkan satu folder untuk menyimpan file, extension *mat (MAT-file).

\section{B. Script File}

Untuk memulai pemograman, klik new document, pilih Srript (Control N) atau klik tombol New Script. Script file dibuat dengan nama tanpa spasi dan dengan ekstensi dot $\mathrm{m}$. Pada tutorial kali ini dibahas mengenai apa itu script file dan cara membuat script file atau mfile pada MatLab. Cara membuat script file atau MFile :

1. Membuat Script File dengan Script Editor, untuk membuat script file baru, klik New Script pada Home Bar MatLab atau tekan Control N pada command window.

2. Mengganti Current Folder (Opsional), Current Folder adalah folder tempat penyimpanan script file maupun GUI, di-index oleh MATLAB untuk menjalankan perintah pada command window.

3. Menulis Program Script File

menulis kode program di script editor. Sintax dasar MatLab:

\section{a. Semicolon (;)}

Semicolon digunakan untuk menjalankan perintah tanpa menampilkan output langsung di command window. Semicolon juga digunakan untuk menjalankan banyak perintah. Semicolon tidak menampilkan output langsung pada command window.

b. Persen $(\%)$

c. Persen digunakan untuk membuat komentar pada kode yang anda tulis. Persen ditulis sebelum kode, ketika anda menekan Enter, kode tidak akan dieksekusi.

d. $\mathrm{Clc}$

Perintah ini digunakan untuk membersihkan layar command window.

e. Clear

Perintah clear digunakan untuk menghapus semua variabel-variabel pada workspace.
Hasil latihan coding menggunkan MatLab:

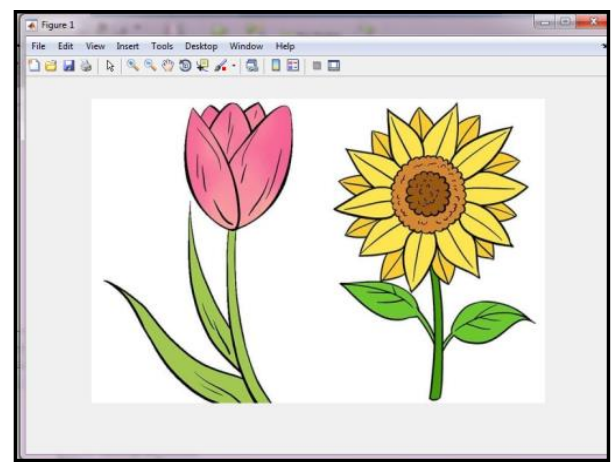

Gambar 7. Tampilan RGB

Menampilkan Gambar Black White

Coding :

citra1_gray= rgb2gray (citra1);

figure, imshow(citra1_gray);

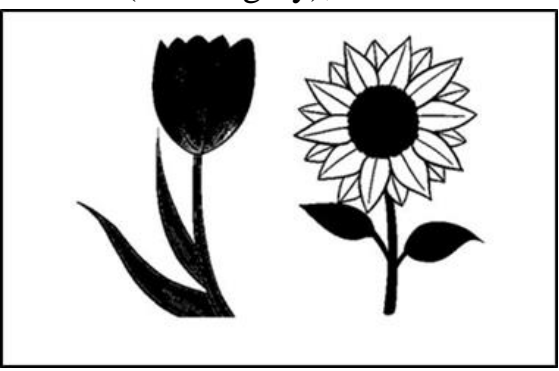

Gambar 8. Tampilan Gambar Black White

Menampilkan gambar dengan background berbedabeda.

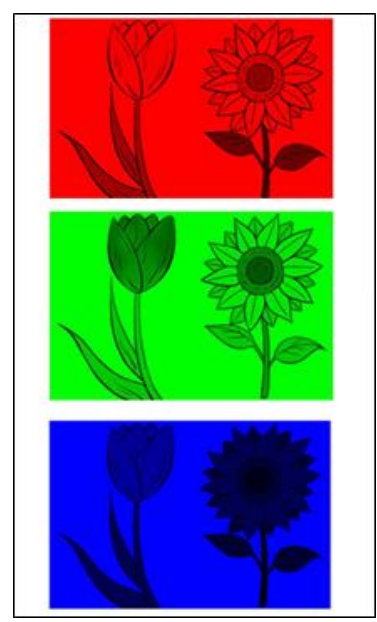

Gambar 9. Hasil Tampilan Program

Perangkat lunak MATLAB tidak hanya menyediakan operasi aritmatika, terdapat juga fungsi matematika untuk penggunaan tingkat lanjut. Terdapat 3 jenis fungsi matematika pada MATLAB yaitu: elementary math function, trigonometric math function, dan rounding function.

A. Menggunakan Fungsi Matematika

MatLab menyediakan fungsi dasar matematika dengan mudah, cukup dengan menggunakan command window. Selain itu fungsi ini juga dapat digunakan 
secara luas seperti dalam script file hingga program yang lebih kompleks.

B. Fungsi Matematika

Fungsi-fungsi dasar matematika yang ada pada library Matlab.

sqrt(x) : Fungsi Akar kuadrat (Square root)

nthroot(x,n) : Fungsi Akar Bilangan Real

> nthroot $(80,5)$

ans $=2.4022$

$\exp (\mathrm{x})$ : Eksponensial Euler $\left(\mathrm{e}^{\wedge} \mathrm{x}\right)$

$$
>\exp (1)
$$$$
\text { ans }=2.7183
$$

abs(x): Nilai Absolut

$$
\text { > abs(-9) }
$$

ans $=9$

factorial $(\mathrm{x})$ : Faktorial $\mathrm{x}$ !

$>$ factorial(3)

ans $=6$

C. Trigonometric Math Functions

Berikut fungsi-fungsi dasar Math Functions:

$\sin (\mathrm{x}) \sin \mathrm{x}$ dalam $\pi$

$\gg \sin (\mathrm{pi} / 2)$

ans $=1$

$\cos (\mathrm{x}) \sin \mathrm{x}$ dalam $\pi$

$>\cos (\mathrm{pi})$

ans $=-1$

$\tan (\mathrm{x}) \tan \mathrm{x}$ dalam $\pi$

> $\tan (\mathrm{pi} / 4)$

ans $=1.0000$

D. Rounding Functions (Fungsi Pembulatan)

Rounding Functions berfungsi untuk membulatkan suatu nilai, pada tabel berikut $\mathrm{x}$ dapat berupa angka maupun operasi aritmatika :

$\operatorname{round}(\mathrm{x})$

Pembulatan ke bilangan bulat terdekat

$$
>\operatorname{round}(2.123+4.5 * 7)
$$

ans $=34$

fix(x) : Pembulatan ke bawah

$$
\text { > fix }(13 / 5)
$$

ans $=2$

ceil(x) : Pembulatan ke atas

$$
>\operatorname{ceil}(2.1)
$$

ans $=3$

floor(x): ke minus tak hingga

> floor(-3.1)

ans $=-4$

rem(x,y) : menampilkan sisa pembagian $\mathrm{x}$ bagi $\mathrm{y}$

$>\operatorname{rem}(13,5)$

ans $=3$

\section{Kesimpulan dan Saran}

Kesimpulan dari pelaksanaan pembelajaran secara daring (online) yaitu kreatifitas berperan penting dalam keberhasilan pembelajaran daring untuk samasama belajar teknologi. Materi pembelajaran disajikan dalam bentuk link video (youtube), materi ini dapat diulang siswa hingga mencapai tujuan pembelajaran.
Saran yang dapat dilakanakan yaitu dasar pembelajaran ini dilanjutkan bagi siswa yang minat mengembangkan bidang teknologi tinggi. Sekolah perlu memperkenalkan teknologi terkini pada siswasiswi dan mendukung siswa yang minat dalam mengembangkan teknologi komputer baik perancangan sistem atau bidang hardware.

\section{Ucapan Terima Kasih}

Terima kasih atas kesempatan dan dukungan pihak Sekolah Swasta Pemda Lubuk Pakam yang telah memberikan waktu pada Tim Pengabdian STMIK Pelita Nusantara berbagi ilmu.

\section{Daftar Rujukan}

Adam, M. (2020). Penyuluhan Bimbingan Jabatan dan Motivasi Kerja-Wednesday InspiringBagi Pencari Kerja Pada Dinas Ketenagakerjaan Kota Balikpapan. Abdimas Universal, 2(1), 17-22.

Dewi, L. (2017). Rancangan Program Pembelajaran Daring Di Perguruan Tinggi: Studi Kasus Pada Mata Kuliah Kurikulum Pembelajaran Di Universitas Pendidikan Indonesia. Jurnal Educational Technology, 2(2), 205-222

Pakpahan, R. (2016). Model Ujian Nasional Berbasis Komputer: Manfaat Dan Tantangan. Jurnal Pendidikan dan Kebudayaan, 1(1), 19-35

Sindar, A. \& Sitorus, M. (2019). Penerapan Teknik Workshop Pada Pembuatan Blog Bagi Pemula Di SMA Al Washliyah 12 Perbaungan. SELAPARANG Jurnal Pengabdian Masyarakat Berkemajuan, 2 (2), 14-18

Sitio, A., \& Sindar, A (2020). Pemanfaaatan IT Dalam Pelaksanaan Ujian Berbasis Komputer pada SMA Negeri 2 Perbaungan. Jurnal Abdimasya, 1(1), 1-9. 